\title{
JUECES Y ARGUMENTACIÓN
}

\section{EDWIN FIGUEROA GUTARRA*}

“No hay mejor forma de ejercitar la imaginación que estudiar la ley. Ningún poeta ha interpretado la naturaleza tan libremente como los abogados interpretan la verdad"

Jean Giraudoux

\section{Resumen}

La construcción de la argumentación de los jueces demanda una correlación de conceptos necesarios que identifica la teoría del derecho, la filosofía del derecho, los derechos fundamentales y las propuestas de las escuelas de la argumentación. El estudio que desarrollamos plantea a este respecto algunas reflexiones iniciales en el propósito de que la labor judicial de sostener razones pueda verse más fortalecida a partir de la identificación de conceptos matrices en relación a las ideas esbozadas.

Palabras clave: Argumentación - Contextos de descubrimiento y justificación - Justificación interna - Justificación externa - Jueces.

\begin{abstract}
The construction of legal arguments by a judge requires the correlation of necessary concepts that identify the theory of law, the philosophy of law, the fundamental rights and the proposal of schools of legal argumentation. Our study offers a few initial thoughts on how the judicial work can be strengthened by identifying core concepts related to proposed ideas and by providing arguments to justify them.
\end{abstract}

Key words: Argumentation - Context of discovery and justification - Internal Justification - External Justification - Judges.

\section{Sumario}

Introducción. 1. La argumentación jurídica. Importancia de su función. 2. Derecho y argumentación. 3. La construcción de argumentos. 4. El ordenamiento jurídico. 5. Contexto de descubrimiento y contexto de justificación. 6. Justificación interna y justificación externa. 7. Teorías de la argumentación jurídica. 7.1. La tópica de Viehweg. 7.2. La retórica de Perelman. 7.3. El discurso racional de Alexy. Conclusiones de interés.

\footnotetext{
* Juez Superior Titular de la Corte Superior de Justicia de Lambayeque - Poder Judicial del Perú. Profesor de la Universidad San Martín de Porres, Filial Chiclayo, Lambayeque y profesor de la Academia de la Magistratura.
} 


\section{INTRODUCCIÓN}

Describir en unas pocas líneas los grandes ejes de la argumentación representa una tarea de suyo ambiciosa en tanto una idea de completitud al respecto resulta muy difícil de manejar si apuntamos a definir todos los ítems más importantes, entre conceptos clásicos de positivismo, no positivismo, teorías precursoras y teorías estándar de la argumentación.

Sin embargo, sí podemos aspirar a puntualizar algunas de las ideas más relevantes en relación a la disciplina de la argumentación, materia que hoy ha asumido una extraordinaria importancia en tanto en todos los ámbitos argumentamos: en nuestras relaciones personales, en los roles institucionales asignados a nuestra formación, y en propiedad, cuando se trata de presentar una tesis que pueda consistir en una demanda o una resolución judicial, ámbito este último en el cual la tarea de argumentar resulta mucho más exigente en cuanto se pretende aportar razones jurídicas consistentes, coherentes y prevalentes.

De ahí el título de nuestra ponencia en cuanto queremos abordar ese rol en especial que les corresponde a los jueces cuando deben argumentar, no en la idea de que fijemos un glosario de pasos necesarios ni alcanzar al famoso juez Hércules en el imaginario de Dworkin, pues versiones al respecto existen muchas, sino procurando destacar la importancia de percibir ese quehacer desde la posición de quien está en la posición de garante de los fundamentos de su decisión, en tanto debe ejercer una función de respaldo de los argumentos que sustentan su posición.

Es nuestro propósito pues poner de relieve algunos conceptos siempre distintivos respecto a la importancia de la argumentación jurídica, partiendo de la necesaria vinculación entre Derecho y argumentación, y en qué medida la construcción de argumentos es una labor ciertamente compleja, para discurrir, de igual modo, por algunas nociones de la argumentación constitucional, en tanto argumentación y derechos fundamentales suelen presentar una vinculación la mayor de las veces estrecha.

A partir de estas nociones de entrada, deviene importante puntualizar las acepciones de ordenamiento jurídico, contextos de descubrimiento y justificación, y en propiedad, justificaciones interna y externa, en tanto son conceptos sucedáneos de la argumentación y todos ellos marcadamente entrelazados, para finalmente abordar un esbozo inicial, corto por razones de espacio, de algunas de las teorías de la argumentación jurídica que más han impactado en los últimos años. 
Ciertamente las teorías han construido importantes estándares para la construcción de argumentos y sin embargo, debemos advertir que la complejidad del Derecho y de misma realidad, tornan en puntos de partida los ejes ancla sobre los cuales reposan las vigas centrales de varias teorías de la argumentación, en tanto y en cuanto el incesante devenir de la realidad y de la riqueza inagotable de los hechos, obligan a revisar permanentemente nuestras propuestas argumentativas, de tal forma que cobra realidad la frase con la cual comienza este estudio, en la medida que la interpretación de la ley por parte de los abogados en el propósito de desarrollar sus asertos de verdad, demanda una gran dosis de imaginación, tarea solo comparable a la de los poetas y más aún, inclusive más exigente que aquella.

Argumentar es, pues, parte de nuestras vidas y en esa reflexión podemos coincidir parafraseando a ORTEGA Y GASSET en el sentido de que construir razones es nuestro ser y circunstancia.

\section{LA ARGUMENTACIÓN JURÍDICA. IMPORTANCIA DE SU FUNCIÓN}

La argumentación jurídica nos enseña a construir las razones con las cuales sustentamos una decisión con relevancia jurídica. La argumentación constitucional, a su turno, reconduce nuestra base argumentativa por el escenario de los derechos fundamentales y determina en qué medida, las pretensiones constitucionales han de merecer una respuesta razonada de los intérpretes autorizados de la Constitución que son en propiedad los jueces constitucionales.

Podemos figurarnos, entonces, que la importancia de la argumentación jurídica radica en que ella permite la plasmación de las justificaciones del juzgador a propósito de su decisión.

Inicialmente el juez se encuentra frente a un problema, identifica a qué alude la controversia sometida a su conocimiento y luego de ello, realiza un examen exhaustivo de los hechos. El contexto de descubrimiento habrá de informarle que será necesario recurrir a su bagaje de conocimientos para asumir determinada posición, será exigible adoptar una posición frente al problema jurídico suscitado y luego de ello, habrá que comenzar a construir la decisión, cuidando de separar en forma ordenada sus argumentos, los cuales unos habrán de constituirse, los complementarios, como obiter dicta, o razones complementarias, y otros tantos, como ratio decidendi, o justificaciones principales del fallo. 
En todo ese ejercicio, habrá de observarse que el esquema de justificación interna sea compatible con el uso de las reglas de la lógica, y es en la justificación externa, al desarrollarse la explicación material de las premisas, que habrá de observarse la importancia de construir buenos argumentos, buenas razones y buenas justificaciones, a propósito de la decisión que cierra el conflicto o que en su caso, implica un análisis razonado de la decisión.

Algunas veces podremos preguntarnos, como hacía GARCía FIGUEROA, que si los jueces han resuelto durante mucho tiempo solo con su conocimiento de la norma y el examen directo de los hechos, y así parecen haberlo hecho durante muchos siglos, ¿por qué esos parámetros hoy tendrían que cambiar? En otros términos, ¿por qué no podremos justificar como se hacía antaño cuando se optaba por validar una decisión que tuviera cuando menos elementos razonables de un ejercicio mínimo pero suficiente de justificación? La respuesta es puntual: porque los parámetros de exigencia de justificación han cambiado sustancialmente.

Argumentar en el siglo XIX se circunscribía al contexto de potestades del juez en el Estado legal de Derecho, en el cual la norma legal o la ley, representaba el punto más alto de interpretación y argumentación para el Derecho.

Hoy esos parámetros han cambiado en varios aspectos: ya no tenemos en estricto un Estado legal de Derecho, que es ciertamente el punto de partida del constitucionalismo moderno, sino existe un Estado constitucional, en el cual la exigencia de justificación es mucho mayor, pues hoy existe un conjunto de derechos -los derechos fundamentales- para los cuales la simple exigencia de justificación en base a la ley es notoriamente insuficiente.

Y no porque la ley haya perdido su valor. No es así en modo alguno. Se trata de que la ley sigue siendo el primer punto de referencia para la resolución de los conflictos, y sigue manteniendo el primer rango de fuente del Derecho respecto a la argumentación en la solución de conflictos. Y sin embargo, la cuestión de que la ley no pueda responder de modo convincente a controversias como las relativas al derecho a la dignidad en su contenido constitucionalmente protegido ${ }^{1}$, como el derecho a vida si se trata de una

\footnotetext{
1 STC 2016-2004-AA/TC. Caso Correa Condori El principio de dignidad de la persona

16. Partiendo de la máxima kantiana, la dignidad de la persona supone el respeto del hombre como fin en sí mismo, premisa que debe estar presente en todas los planes de acción social del Estado suministrando una base constitucional a sus políticas, pues en el Estado social el respeto a la dignidad se refiere esencialmente a lograr una mejor calidad de vida de las personas.

Consecuentemente, en sede jurisdiccional ningún análisis puede desarrollarse sin verificar el respeto a la dignidad del hombre, tanto en la actuación del Estado como en la de los particulares.
} 
cuestión de zanjar posiciones respecto al origen de la misma ${ }^{2}$, o como las fronteras propias entre el derecho al honor y el derecho a la información, entre otras asuntos de actualidad, nos llevan a pensar en que efectivamente se necesita otros parámetros argumentativos frente a la importancia creciente de los derechos fundamentales.

De esa forma, no es lo mismo argumentar solo en base a los ámbitos de vigencia y validez formal de la norma jurídica, que hacerlo desde la perspectiva de los derechos fundamentales, en función a los contenidos de juridicidad y de moralidad de estos derechos.

Es pertinente pues remarcar el valor axiológico de los derechos denominados fundamentales, en cuanto ello permite un margen de diferenciación de los derechos denominados de origen legal, o de configuración legal si nos referimos a los derechos que resisten un ámbito de efectividad respecto de la norma jurídica.

Es en esa perspectiva que la argumentación cumple una función primordial dentro de la justificación externa en tanto en su decurso los jueces propiamente interpretan las normas de origen legal y constitucional, así como proceden a una lectura de los hechos de acuerdo a las controversias propias de la controversia materia de examen.

Es decir, el proceso de interpretación, tan importante en el derecho, se produce cuando argumentamos, denotándose un efecto de interrelación muy estrecho entre argumentación e interpretación, no de rango mayor a menor ni viceversa, sino de inter ejecución de ambos ejercicios racionales, pues al argumentar realizamos interpretación de la norma y los hechos, y al interpretar, igualmente desarrollamos un ejercicio de argumentación.

No se trata, sin embargo, de lecturas iguales en cuanto la interpretación obedece más a un contexto de lectura de comprensión de los sentidos de la norma y de los hechos, en tanto que argumentar es, en propiedad, un

\footnotetext{
2 STC. ${ }^{\circ}$ 02005-2009-PA/TC. Caso ONG Acción de Lucha Anticorrupción, de la Píldora del día siguiente 4.2. Teorías sobre el inicio de la vida

14. Desde el punto de vista de la ciencia médica existen diversas teorías que pretenden identificar el momento en el que la vida humana empieza. Hay quienes consideran que la vida humana surge desde el instante en que se inicia la actividad cerebral (aproximadamente la sexta semana contada desde la fecundación), pues resulta lógico que si la persona llega a su fin con el estado irreversible de las funciones cerebrales, de la misma manera la actividad cerebral daría inicio a la vida. Sin embargo, las más importantes considerando el número de seguidores, y que justamente han sido ampliamente debatidas a partir del caso en cuestión, se encuentran en la llamada Teoría de la Fecundación, basada principalmente en la existencia, ya en esta instancia, de una nueva individualidad genética; y la Teoría de la Anidación, fundamentada en la viabilidad del embrión y la certeza del embarazo.
} 
ejercicio de construcción de razones que a su vez van a resultar muy útiles para consolidar el ejercicio de motivación que exige el artículo 139 inciso 5 de la Carta Fundamental.

Podemos perfilar, en ese propósito, que toda pretensión, al igual que toda decisión jurisdiccional, representa un ejercicio de construcción de argumentos y un argumento, asume la forma de una razón.

Tanto los abogados como los jueces y fiscales se encuentran obligados a que sus argumentos constituyan razones valederas, consistentes y coherentes, con marcado énfasis de responsabilidad para los jueces en mayor grado pues existe un mandato constitucional de motivación, cuya infracción implica incurrir en vulneración ${ }^{3}$ de un derecho fundamental.

\section{DERECHO Y ARGUMENTACIÓN}

Describir las relaciones entre Derecho y argumentación pasa por un necesario examen histórico de las exigencias argumentativas frente al Derecho. En efecto, a partir del modelo de justificación vigente es que podemos identificar el escenario de dimensión argumentativa del Derecho. Y dentro de esa línea argumentativa, observaremos la relevancia de los derechos fundamentales en relación con la argumentación en el Estado constitucional.

Por la Ley del Talión "Ojo por ojo, diente por diente", desde el Código de Hammurabi, el Derecho solo podía entenderse como una reacción proporcional, sin contenido alguno adicional, salvo el de la respuesta de igual forma a la ofensa, criterio que a su vez representó hasta una pauta de equivalencia, dadas las venganzas desmedidas ${ }^{4}$ que el mundo sufría antes de la Ley del Talión.

A partir del iusnaturalismo, entre cuyos representantes podemos referir a GROCIO, AlTHUSIUS, LOCKE, HOBBES y ROUSSEAU, la relación entre Derecho y argumentación se ciñó a una subordinación del derecho en su conjunto, a una

3 STC 00728-2008-PHC/TC Caso Giuliana LLAMOJA.

El fundamento jurídico 7 describe las siguientes categorías contrarias a una debida motivación: Inexistencia de motivación o motivación aparente, falta de motivación interna del razonamiento, deficiencias en la motivación externa, motivación insuficiente y motivación sustancialmente incongruente.

4 La Biblia refiere en Génesis 34,1,31, que una joven de nombre Dina fue agredida sexualmente por un hombre llamado Siquem. En venganza, los hermanos de ella mataron al violador, a su padre y a todos los jóvenes de sexo masculino de la ciudad. Vista de esta forma, la Ley del Talión representó una idea de proporcionalidad, en comparación a las venganzas que permitían crímenes desmedidos. 
razón inmanente, natural, divina, cuya argumentación solo podía sujetarse a fundamentar las razones de esa noción de trascendencia superior y de más allá de las fronteras espirituales.

En la España del siglo XVIII, por Real Cédula dictada en junio de $1768^{5}$, el Rey Carlos III de España prohibió a la Audiencia y demás jueces de Mallorca la práctica de motivar las sentencias que hasta entonces se observaba. Se señalaba al efecto:

"Para evitar los perjuicios que resultan con la práctica que observa la Audiencia de Mallorca, de motivar sus sentencias, dando lugar a cavilaciones de los litigantes, consumiendo mucho tiempo en la extensión de las sentencias, que vienen a ser un resumen del proceso, y las costas que a las partes se siguen; mando cese en dicha práctica de motivar sus sentencias, ateniéndose a las palabras decisorias, como se observa en el mi Consejo, y en la mayor parte de los Tribunales del Reino; y que a ejemplo de lo que va prevenido a la Audiencia de Mallorca, los Tribunales ordinarios, incluso los privilegiados, excusen motivar las sentencias como hasta aqui, con los vistos $y$ atentos en que el hecho de los autos y los fundamentos alegados a las partes; derogando, como en esta parte derogo, el auto acordado 22, Tít. $2^{\circ}$, Libro $3^{\circ}$, duda $4^{a}$ Rec. u otra cualquiera resolución o estilo en contrario"

La noción del Estado de Derecho transforma progresivamente los esquemas de unilateralidad de la razón en exigencias argumentativas de aporte de fundamentos para la validez de las decisiones jurídicas. Por tanto, en vía de ejemplo, una condena impuesta en una sentencia en los albores del Estado de Derecho, ya debía cuando menos justificar las razones de forma y fondo para la validez de la decisión. En forma paulatina, el Derecho comienza convertirse en un mecanismo de respuesta, efectividad y solución de los conflictos jurídicos, frente a los cuales debía cumplirse la configuración de razones válidas, congruentes y suficientes para la validez de una decisión, más aún si ella era jurisdiccional.

La irrupción del Estado constitucional, cuya tesis es la Constitución como cúspide del ordenamiento jurídico, consolida la exigencia de una argumentación, formal y material, para la validación de las decisiones con

\footnotetext{
GHIRARDI se refiere a la Real Cédula de 1778 (Ghirardi, Teoría y práctica del razonamiento forense. Advocatus, Córdova, 1999, p. 15), sin embargo, precisan Carlos Garriga y Marta Lorente, siguiendo a J.M. Mariluz Urquijo que la fecha correcta es de 1768. (GARRIGA, Carlos - LORENTE, Marta: «El Juez y la Ley. La Motivación de las Sentencias (Castilla, 1489 - España, 1855)». En: La Vinculación del Juez a la ley. Anuario de la Facultad de Derecho de la Universidad Autónoma de Madrid. Madrid, 1997, p. 101, nota 17). En SANTA CRUZ, Julio César. «Razonamiento Jurídico». Diplomatura de Formación Profesional para Jueces del Segundo y Tercer Nivel de la Magistratura. Academia de la Magistratura, 2010, p. 14.
} 
relevancia jurídica. En ese caso, la argumentación ya no es solo una potestad que debe impulsar el Estado, sino una necesidad para la legitimación de las decisiones en ese Estado con principios, valores y directrices de contenido constitucional.

La Declaración Universal de los Derechos Humanos (1948), la Ley Fundamental de Bonn (Alemania,1949), las Constituciones de Francia (1958) y España (1978), se orientan a consolidar como exigencia de todo Estado la observancia el respeto y la defensa de los derechos fundamentales, premisas a partir de las cuales podemos inferir, con suficiencia, que la debida motivación de las resoluciones judiciales, constituye un ejercicio de argumentación como singular expresión de una democracia viviente y no solo existente.

Perú se suma a esa ruta de exigencia con sus Constituciones de 1979, la Constitución modélica, y 1993, así como aporta a la exigencia de motivación su Código Procesal Constitucional de 2004, el cual exige que las decisiones,

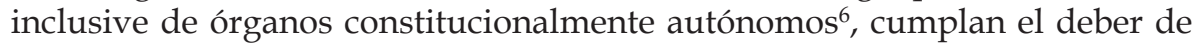
motivar sus decisiones.

Es posible observar, a partir de estas menciones de orden histórico, la necesidad de identificar un estrecho nivel de relación entre cómo se configura el Derecho en determinado momento histórico, y cómo, a partir de esa percepción, tiene lugar el proceso argumentativo.

En una idea resumen, podemos establecer que las relaciones históricas entre Derechoy argumentación se han orientado a que la exigencia de argumentación se ha ido incrementando, a medida que los derechos de las personas han ido progresivamente impregnándose de mayor contenido y a medida que los derechos fundamentales, con su crecimiento vía las tesis constitucionales de derechos no enumerados e incorporados paulatinamente al ordenamiento constitucional, han ido transformando las potestades de orden facultativo de argumentación, en sendos deberes de raigambre constitucional.

\footnotetext{
6 Inicialmente, el voto de los consejeros del Consejo Nacional de la Magistratura, en los procesos de ratificación desarrollados conforme al artículo 154 inciso 2 de la Constitución, involucraban solo un voto de confianza y como tal, la justificación no era exigible. El Código Procesal Constitucional y el desarrollo jurisprudencial de la exigencia de la motivación, en cuyo caso el proceso Álvarez Guillén aquí reseñado es emblemático, han modificado sustancialmente ese panorama y desde la vigencia de la nueva herramienta procesal constitucional, la motivación en los procesos de ratificación, resulta un derecho de los magistrados. Y creemos que la perspectiva de análisis es puntual en el siguiente aspecto; si el magistrado laboró 7 años al servicio del Estado, concluido ese período, dicho magistrado como ciudadano, tiene derecho a saber por qué no se la ratifica y se determina la conclusión de su contrato de trabajo. A ello apunta la motivación constitucional en el tema de la ratificación de magistrados.

Vid también STC 3361-2004-AA/TC. Caso Jaime Álvarez Guillén.
} 
Bajo esa pauta, hoy el Derecho es argumentación y la argumentación es Derecho, en una relación indisoluble cuya base se ciñe a las exigencias de un Estado constitucional.

\section{LA CONSTRUCCIÓN DE ARGUMENTOS}

¿Qué significa construir argumentos? ¿Se trata de una labor meramente teórica y abstracta? ¿Implica ello para el juez cerrarse en su gabinete y ejercer una construcción de ideas hondamente esquemáticas y abstractas? ¿Es una buena sentencia aquélla que abunda en argumentos de Derecho? ¿O es mejor sentencia aquella que es eminentemente práctica?

Vamos por partes. Construir argumentos es una labor de construcción de razones. Significa, en buena cuenta, aplicar lógica, interpretación, desarrollar motivación suficiente y exige de parte de los jueces, constante preparación, formación, lectura, identificación con el trabajo, cultura jurídica, entre otras virtudes necesarias para desarrollar una buena argumentación.

Manuel ATIENZA ${ }^{7}$ desarrolla hasta 10 buenas razones para argumentar bien, las cuales son, a juicio nuestro, un excelente punto de partida, para rescatar las nociones de entrada en toda argumentación que quiera preciarse de suficiente.

De otro lado, la argumentación no es una tarea por entero abstracta. Es abstracto el razonamiento del juez para llegar a una conclusión pero una

7 ATIENZA, Manuel. «Diez consejos para argumentar bien o decálogo del buen argumentador». Doxa, Cuadernos de Filosofía del Derecho, No. 29 (2006).

"1. El mejor consejo que puede darse a quien desee argumentar bien en el Derecho o en cualquier otro ámbito es prepararse bien".

"2. Hay aspectos comunes a cualquier tipo de argumentación, pero también rasgos peculiares de cada campo, de cada tipo de debate. Por ejemplo, lo que es apropiado para una conferencia (la exposición por extenso de una tesis) no lo es para el que participa en una mesa redonda...".

"3. $\quad$ No se argumenta mejor por decir muchas veces lo mismo, ni por expresar con muchas palabras lo que podría decirse con muchas menos".

“4. En una discusión, en un debate racional, esforzarse porque el otro tenga razón-como alguna vez propuso Borgesparece demasiado".

"5. Cuando se argumenta en defensa de una tesis, no estar dispuesto a conceder nunca nada al adversario es una estrategia incorrecta y equivocada".

"6. Cuando se argumenta con otro, uno puede tener la impresión de que los argumentos de la parte contraria funcionan como una muralla contra la que chocan una y otra vez nuestras razones. Por eso, una vez probada la solidez de esa defensa, lo más aconsejable es ver si uno puede tomar la fortaleza intentando otra vía".

"7. La argumentación no está reñida con el sentido del humor, pero sí con la pérdida del sentido de la medida".

"8. No se argumenta bien por hacer muchas referencias a palabras prestigiosas, autores de moda, etc. Lo que cuenta es lo que se dice y las razones que lo avalan...".

"9. Frente a la tendencia, natural quizás en algunas culturas, a irse por las ramas no cabe otro remedio que insistir una y otra vez en ir al punto, en fijar cuidadosamente la cuestión".

"10. En cada ocasión, hay muchas maneras de argumentar mal y quizás más de una de hacerlo bien". 
vez que el problema ha sido enfocado, el desarrollo del problema debe ser eminentemente pragmático pues partimos de la tesis de que un conflicto es un hecho real que tiene que ser dilucidado. Como refiere AtienZA : "Si se quiere, al lado del lema: "la enseñanza del Derecho ha de ser más práctica", tendría que figurar este otro: "!no hay nada más práctico que la buena teoría y el núcleo de la buena teoría jurídica es argumentación!".

De esta tesis de hondo significado, podemos extraer que la argumentación debe ser buena teoría para que las decisiones con contenido jurídico sean fiel expresión del deber de resolver una controversia, cual fuere su naturaleza.

\section{EL ORDENAMIENTO JURÍDICO}

Precisadas las nociones que anteceden en conceptos de entrada al complejo mundo de la argumentación, queremos rescatar ahora, hasta 3 acepciones relevantes: el ordenamiento jurídico en la concepción de Norberto BOBBIO, los contextos de descubrimiento y de justificación así como las nociones de justificación interna y externa, conceptos todos estos que se interrelacionan en tanto exigimos un ordenamiento que evite incoherencias y lagunas para que en el mismo los intérpretes desarrollen la justificación de sus pretensiones, las cuales deben respetar, del mismo modo, reglas mínimas de no contradicción y desarrollo material de las premisas.

Fijadas esas ideas, podemos realizar un esbozo de cuáles son los aportes más importantes de diversas teorías de la argumentación jurídica.

En su concepto de orden normativo sistémico y aunque pudiera eventualmente criticarse que ésta sea una tesis positivista ${ }^{9}$, convenimos con Norberto BOBBIO $^{10}$ en que el ordenamiento jurídico goza de 3 caracteres esenciales: unidad, coherencia y plenitud.

De unidad, por cuanto las decenas de miles de normas y leyes existentes, sin contar otros tantos dispositivos reglamentarios, forman un todo armónico con la Constitución, en el sentido de que todas esas reglas, aún las que pudieran en determinado momento colisionar con la misma, forman una unidad

\footnotetext{
8 ATIENZA, Manuel. «Las razones del Derecho». Palestra- Lima, 2004, p. 18.

9 La tesis del positivismo jurídico pretende asumir una noción de certeza, seguridad y fortaleza del Derecho sobre la base de que la norma jurídica debe responder con suficiencia al conflicto planteado. El positivismo se presenta como un método, una teoría y una ideología. Cfr. BOBBIO, Norberto. «El problema del positivismo jurídico». Fontamara, México, 1991. p. 89.

10 BоввIO, Norberto. «Teoría del Ordenamiento Jurídico», 1960. En Introducción al Derecho de José Luis del HIERRO. Editorial Síntesis, Madrid, 1997. p. 95.
} 
representativa, en la cual en la cúspide de esa pirámide, la Constitución no es solo una norma más, sino la norma que realmente vincula a todos los poderes y por consiguiente, a todas las normas con rango de ley y administrativas.

De coherencia, en razón de que el todo armónico que acabamos de reseñar en realidad puede presentar en algún momento contradicciones respecto a sus contenidos, esto es, normas que pudieran eventualmente contradecirse cuando de pretensiones judiciales contrarias pudiera tratarse, y sin embargo, esas incoherencias son resueltas por los jueces del Estado constitucional de diversas formas: sea por los métodos de solución de antinomias bajo los criterios ley superior derogat inferior, ley posterior derogat anterior o lex specialis derogat generalis ${ }^{11}$ cuando se trata de conflictos normativos, o sea bajo otros parámetros como la ponderación y el principio de proporcionalidad, entre otros, si se trata de colisiones de principios, también denominados derechos fundamentales, o por extensión, normas-principios.

Y de plenitud, en vista de que las lagunas o vacíos del ordenamiento jurídico necesariamente y sin excusa, deben ser colmados. Es decir que, ante los conflictos normativos o las colisiones de principios, no pueden prevalecer vacíos más allá del simple examen inicial de la pretensión.

El Juez podrá advertir, frente a determinado caso, que si bien no hay una norma-regla aplicable al caso que debe resolver, o que no existe una ley o reglamento que pueda resolver la controversia, no por esta razón habrá de excusarse de solucionar el caso.

En tal sentido, tendrá que invocar principios, entendidos como mandatos de optimización, para poder dar solución al conflicto o controversia materia de análisis. Y más aún cuando se trata de derechos fundamentales, pues en rigor éstos tienen la premisa de optimizar los contenidos de pretensiones hasta donde sea racional y razonable tutelar un derecho iusfundamental frente a una afectación manifiesta a su contenido.

De ahí que podamos entender, también, la teoría del Derecho Constitucional, como una teoría de la integración ${ }^{12}$, en el propósito de que siendo insuficiente

${ }_{11}$ La traducción literal sería: "La ley superior deroga a la inferior; la ley posterior deroga a la anterior; y la ley especial deroga a la ley general". Sin embargo, la referencia es efectuada en un sentido de prevalencia de una ley sobre otra, sin llegar necesariamente a la derogación.

12 Cfr. Lucas Verdú, Pablo. «La lucha contra el positivismo jurídico en la República de Weimar. La teoría constitucional de Rudolf Smend», Ed. Tecnos, Madrid, 1987. En Revista de Estudios Políticos (Nueva Época). Núm. 59. Enero-Marzo 1988, p. 269. 
resolver los conflictos con la ayuda de las normas-regla, deba acudirse a los contenidos de las normas-principio como manifestaciones de optimización de los derechos fundamentales.

En consecuencia, todo ordenamiento jurídico puede a su vez ser entendido como un ordenamiento constitucional en el cual la Constitución regula como un todo armónico, coherente y pleno las relaciones entre los derechos fundamentales de los ciudadanos del Estado constitucional.

\section{Contexto de descubrimiento y contexto de justificación}

Las diferencias centrales entre contexto de descubrimiento y contexto de justificación se ciñen a la exigibilidad de justificación cuando argumentamos una decisión.

En relación al contexto de descubrimiento, podemos esbozar un ejemplo conforme a un ejemplo clásico de GARCía FIGUEROA ${ }^{13}$ en el sentido siguiente: ¿podríamos exigirle a alguien explicar por qué le gusta el helado de vainilla? Podría en nuestro caso interrogársenos ¿tiene relevancia jurídica por qué hemos estudiado Derecho? O una pregunta más aún de contexto general ¿por qué unos vemos el vaso medio vacío y otros solemos verlo medio lleno?

El contexto de descubrimiento no asume relevancia en la argumentación constitucional en tanto no es exigible, racionalmente, la explicación de por qué se adoptó una u otra posición interpretativa pues en gran medida, este tipo de contexto tiene lugar respecto a los criterios de valoración del juez, a su formación, a su propia idiosincrasia frente a determinados problemas, a cómo ve un determinado problema con relevancia constitucional, entre otros fundamentos de su fuero interno.

En otra vía de ejemplo, los jueces de las zonas alejadas de la Costa, en donde las poblaciones -léase Comunidades Nativas- conservan valores distintos a los de las zonas urbanas en temas de represión de conductas antijurídicas, podrían asumir que constituya una conducta permitida que ciertos sectores de la población nativa puedan comprometerse y procrear familia desde temprana edad, en tanto que un juez de la Costa, más ceñido a valores de protección vertical de la indemnidad sexual de menores, sí consideraría la apertura de un proceso penal por cuestiones vinculadas a la protección estatal

13 García FigueroA, Alfonso y Marina GasCon AbELlán. «La argumentación en el derecho». Algunas cuestiones fundamentales. Palestra Editores, Lima, 2003, p. 60. 
en caso de la unión marital con una persona menor de edad.

En el caso en comento, el contexto de descubrimiento del juez del entorno rural, expresado como su formación moral, social y de valores, informaría que no habría mérito para la imposición de una sanción penal, y en rigor el contexto de descubrimiento no es un ítem susceptible de examen pues el fuero interno obedece a un conjunto de razones determinadas para apuntar a una solución del conflicto.

La dimensión del problema, en términos de justificación, es otra cuando nos referimos al contexto de justificación. Las condiciones en este caso sí son diferentes pues el contexto de justificación asume relevancia jurídica en tanto el juez debe explicar, sustentar y argumentar por qué su decisión asume el sentido finalmente adoptado. En rigor, en el contexto de justificación, la sociedad abierta de intérpretes que somos todos los seres humanos con capacidad de raciocinio, siguiendo la noción hâberleana, nos vemos en la necesidad, exigencia y requerimiento de fundamentar nuestras decisiones, a diferencia del contexto de descubrimiento, el cual solo enuncia nuestra posición.

Es en ese sentido cuando cobra una dimensión jurídico garantista la decisión del juez que debe sustentar una posición y las implicancias constitucionales son de suyo relevantes. Bajo los alcances del contexto de descubrimiento, no se le requerirá al juez por qué adoptó una decisión, o de qué manera se expresó ese fuero interno propio del mismo para entender que en un caso determinado, verbigracia, no adoptó una posición de tutela o de improcedencia. Tampoco sería viable, bajo las reglas del contexto de descubrimiento, por qué el juez partió de determinados supuestos para señalar que la pretensión constitucional sí debía declararse fundada.

Sin embargo, en el contexto de justificación el juez se ve impelido para expresar, una a una, las razones, normativas, fácticas o de principios, que le conceden fuerza a su decisión y que propiamente satisfacen la exigencia de una justificación.

Anteponer el contexto de descubrimiento como sustento de una decisión, en consecuencia, equivaldría a adoptar una posición subjetiva, en propiedad arbitraria o irracional. Sería asumir la posición de Luis XIV en la Francia del siglo XVII, al afirmar: "El Estado soy yo"14, cuya equivalencia a un contexto

$\overline{14}$ "L'Etat c'est moi". Luis XIV, también llamado el Rey Sol. Aunque la cita es acusada de apócrifa, la frase pudo 
de actualidad se acercaría a justificar que una sentencia ha sido expedida en la forma que lo fue, porque ése es simplemente el parecer del juez.

El contexto de justificación, apreciamos entonces, nos conduce a otro escenario de la argumentación: el necesario aporte de razones que a su vez determinen, racional y razonablemente, por qué el juez falló en la forma que lo hizo.

De ahí la importancia de la existencia de un contexto de justificación pues a través del mismo, como comunidad jurídica y bajo sustento constitucional ${ }^{15}$, exigimos a los jueces una tarea de justificación sólida, coherente y consistente. Si la decisión judicial adolece de estas condiciones mínimas, se abren las puertas del necesario ejercicio de corrección bajo las reglas del principio de pluralidad de instancias. En consecuencia, una decisión constitucional sin un ejercicio adecuado de argumentación, debe ser dejada sin efecto.

\section{JUSTIFICACIÓN INTERNA Y JUSTIFICACIÓN EXTERNA}

¿Por qué dividir la justificación en interna y externa? Fundamentalmente a efectos de dividir la decisión en 2 planos: por la justificación interna, apreciamos si el juez ha seguido un ejercicio de sindéresis lógica y revisamos, con insistencia, si el juez ha seguido las reglas de la lógica formal.

Analizamos en el plano de justificación interna, si el fallo ha sido cuidadoso en no entrar en contradicciones manifiestamente incongruentes. Verificamos si las premisas fácticas de vulneración de un derecho fundamental se adecuan y tipifican dentro de la norma tutelar constitucional o infraconstitucional.

En realidad, la decisión constitucional muchas veces constituye un conjunto considerable de premisas mayores o principios, valores y directrices, a cuyo ámbito se remiten igual número de hechos o circunstancias fácticas vinculadas a vulneraciones. En tal sentido, podemos apreciar un número considerable de razones que exigen ser delimitadas a través de un ejercicio lógico que denote que efectivamente hay una secuencia de congruencia, de íter procedimental lógico y que no se han producido cuando menos contradicciones entre las premisas mayores y las premisas fácticas, o entre los principios rectores de tutela y las circunstancias de hecho expuestas.

derivar de la idea "El bien del Estado constituye la Gloria del Rey", sacada de sus Reflexiones. El sentido de la frase es vinculada al absolutismo político.

15 Constitución 1993. Artículo 139 inc. 5:

Son principios y derechos de la función jurisdiccional:

"5. La motivación escrita de las resoluciones judiciales en todas las instancias, excepto los decretos de mero trámite,

con mención expresa de la ley aplicable y de los fundamentos de hecho en que se sustentan". 
La tarea del juez constitucional, en estos casos, es acometer con mucho cuidado su tarea de construcción de argumentos y no podrá, en vía de ejemplo, resolver de forma desestimatoria una pretensión vinculada al derecho fundamental a la salud, unida a la norma-principio del derecho a la vida, si ya existe un antecedente jurisprudencial ${ }^{16}$ que sienta doctrina constitucional respecto a una tutela.

El juez no podrá alegar que conoce el antecedente pero que considera restarle validez. ¿Por qué? Porque en caso de una sentencia denegatoria, en la cual desestima la pretensión, cuando menos una de las construcciones lógicas que no existe tutela del derecho fundamental a la salud cuando sí existe en otro caso resuelto por el supremo intérprete de la Constitución- devendría falsa.

Veamos esto con objetividad: creeríamos que el juez, al denegar el caso, infringiría un principio de la lógica formal: daría como cierto un hecho falso. En consecuencia, se consolida una manifiesta contradicción en su razonamiento y esa decisión es susceptible de ser atacada por un problema de justificación interna.

En otro ámbito, la justificación externa se acerca mucho más a una justificación material de las premisas: implica un ejercicio de justificación que bien podría ser óptimo, cuando justifica su decisión en base a la ley, la doctrina y la jurisprudencia ${ }^{17}$, o bien cuando recurre a un ejercicio mínimo suficiente de la justificación, es decir, aporta cuando menos una sustentación que satisface los requisitos liminares de una justificación suficiente.

En la justificación externa, atendemos fundamentalmente a que en los casos en sede constitucional, los principios que justifican la decisión hubieren sido óptimamente delimitados, y que los hechos que rodean el caso, hubieren

\footnotetext{
${ }^{16}$ Vid. STC 2945-2003.AA/TC caso Azanca Meza, sobre atención médica integral para pacientes con VIH/ SIDA

6. “... en nuestro ordenamiento jurídico el derecho a la salud no se encuentra contemplado entre los derechos fundamentales establecidos en el artículo $2^{\circ}$ de la Constitución, sino más bien se lo reconoce en el capítulo de los derechos económicos y sociales a que se refieren los artículos $7^{\circ}$ y $9^{\circ}$ de la Constitución, este Tribunal, al igual que nuestro similar colombiano, considera que cuando la vulneración del derecho a la salud compromete otros derechos fundamentales, como el derecho a la vida, la integridad física o el libre desarrollo de la personalidad, tal derecho adquiere carácter de derecho fundamental y, por tanto, su afectación merece protección vía la acción de amparo (STC N. ${ }^{\circ}$ T- 499 Corte Constitucional de Colombia".

17 Vid. GASCÓN ABELLÁN, Marina. «Los argumentos de la interpretación». En Razonamiento Jurídico. XII Curso de Ascenso Academia de la Magistratura. p. 70.

Marina GASCÓN ABELLÁN señala:"Los argumentos que sostienen la justificación externa de la premisa normativa pueden ser de tres tipos: el respeto a la ley (en particular las definiciones legislativas, las leyes interpretativas y los métodos de interpretación), los argumentos de la dogmática y el recurso a los precedentes".
} 
correspondido a una adecuada enunciación fáctica. Solo en esos casos, puede entenderse debidamente cumplido el ejercicio de justificación externa.

Por tanto, toda decisión judicial debe satisfacer los estándares de justificación interna y externa, en tanto la ausencia de una $u$ otra, no permite la validez de la misma, asumiendo que la validez es en rigor, un ejercicio de compatibilidad con la Constitución, es decir, con los principios, valores y directrices de la Carta Magna.

\section{TEORÍAS DE LA ARGUMENTACIÓN JURÍDICA}

Es importante observar, a grandes rasgos, cuáles son las teorías de argumentación jurídica que han marcado un espacio determinado de influencia en el pensamiento jurídico contemporáneo para, a partir de las mismas, esbozar nuestros lineamientos centrales sobre la argumentación constitucional.

Los criterios de estas teorías constituyen una clara influencia sobre el pensamiento constitucional moderno y su conocimiento debe afianzar una visión en rigor amplia de las corrientes más representativas.

Comenzamos por analizar las posiciones de VIEHWEG y Perelman, quienes representan una tendencia que comienza a señalar que es necesario aportar otras fuentes de análisis para una mejor argumentación, descartando la mera lógica formal; y luego principalmente a ALEXY, quien en rigor representan la teoría estándar de la argumentación jurídica por la presencia significativa del contexto de justificación como escenario que obliga al aporte de razones.

\subsection{La tópica de VIEHWEG}

Según ATIENZA, ${ }^{18}$ Theodor VIEHWEg (Leipzig, Alemania, 1907- Mainz, Alemania, 1988) pretende revitalizar la tópica. Refiere que los lugares comunes, los tópicos, las opiniones asumidas generalizadamente, nos pueden ahorrar un considerable esfuerzo fundamentador.

Lo importante no es lo que dice el Código, sino cómo resolver el caso aquí y ahora, y entonces entran en juego las técnicas de la tópica jurídica, los lugares comunes socialmente aceptados, la tradición jurídica compartida, etc.

\footnotetext{
18 VIEHWEG, Theodor. «Topik und Jusrisprudenz». En Las Razones del Derecho de Manuel Atienza. p. 71.
} 
Y aún cuando García AMADO le critica a VIEHWEG su vaguedad, pluriformidad e indefinición metodológica, es innegable el gran valor anticipatorio de la teoría de Viehweg, al potenciar la perspectiva argumentativa desde una posición que se esfuerza por compatibilizar la práctica con la razón y la justicia.

Pero no solo este es el aporte de VIEHWEG a la disciplina de la argumentación. Sus propuestas tópicas rompen, de igual forma, con la hegemonía de la lógica formal para replantear que podía igualmente argumentarse, y de mejor modo, desde una alternativa distinta a la presentada, hasta entonces, por la lógica propiamente dicha, cuyos esquemas formales, de la mano de una secuencia positivista del Derecho, ya no brindaban una respuesta satisfactoria a las cuestiones controversiales del Derecho y que por lo tanto, exigían una nueva forma de argumentar.

La tópica, en esa forma, implicaba razonar a partir de problemas o casos con la idea de presentar una "jurisprudencia de problemas"19, en la idea de proyectar "conclusiones que derivan de proposiciones que parecen verdaderas con arreglo a una opinión acreditada" 20 .

La tópica consistiría en el siguiente método: "Cuando se quiere hacer una pregunta lo primero que se tiene que descubrir es el tópico que debe emplearse para obtener la conclusión dialéctica; en segundo lugar, se deben plantear en sí mismas las preguntas concretas, llevándolas con un determinado orden; $y$, por último, dirigirlas adecuadamente al interlocutor" ${ }^{21}$.

Ciertamente la tópica apunta a una especie de lugar de donde se extraen materiales, propiamente argumentos, para una demostración de razones y aún cuando no percibimos una verdadera sistematización de la propuesta, es innegable concluir que la propuesta se diferencia de la propuesta de lo lógica formal de completitud de sus argumentos desde una perspectiva del Derecho capaz de dar respuesta, desde la norma jurídica, a todas las cuestiones controversiales, reto que las corrientes positivistas ya no podían asumir y que Viehweg, al publicar Topik und Jurisprudenz en 1953, se anticipa a proyectar.

\footnotetext{
19 Morelli, Mariano G. «Pensar el derecho desde el problema. Theodor VIEHWEG: Tópica y Sistema en la Historia del Derecho». Disponible en:

http://www.cartapacio.edu.ar/ojs/index.php/iyd/article/viewFile/815/1446

${ }^{20}$ MorelLI, Mariano G. Op cit., p. 8.

21 ARISTÓteles. «Topika». Libro VII. 1,2. En VIEHWEG, Theodor. «Tópica y Jurisprudencia», Madrid, Ed. Taurus, 1986, traducción de Luis Díez-Picazo Ponce de León. P. 41. En Morelli, Mariano G. Op cit., p. 8.
} 


\subsection{La retórica de Perelman}

La retórica de Chaim Perelman (Varsovia, Polonia, 1912- Bruselas, Bélgica, 1984) constituye una de las apuestas más interesantes por rescatar el concepto persuasivo de la argumentación, a partir de la importancia de su correlación con la retórica del mundo griego, revitalizando así los conceptos de Aristóteles sobre la legitimidad filosófica de la retórica y relegando la condena de Platón frente a esta disciplina, en tanto la solía asociar a la sofística y a la manipulación de la verdad.

Se inserta esta propuesta, conjuntamente con la de Theodor Viehweg, propulsor de la tópica jurídica, en la exigencia de descartar los métodos de la lógica estrictamente formal para el desarrollo de las cuestiones de derecho.

La tesis de PERELMAN sustenta la prevalencia de la persuasión como elemento prevalente en el discurso argumentativo, a efectos de convencer a los demás de nuestra posición. Diríamos que esta tesis se acerca mucho a la idea de pretensión de corrección de ALEXY, más basados en que nos dirigimos a un auditorio particular y a un auditorio universal, respecto de los cuales es necesario que nuestro discurso persuada, explique y convenza. Precisamente la exigencia de adhesión de ese auditorio a las ideas, explica la figura de la importancia de la persuasión.

A propósito de la diferencia de los niveles de persuasión, es importante rescatar la diferencia que hace GUASTINI ${ }^{22}$, dentro de los alcances de la interpretación correctora, entre la tarea del abogado, la cual denomina es de valoración, elección y decisión, y la labor del juez, a la cual le asigna un contenido hondamente racional, en cuanto su tarea es sustantivamente cognoscitiva.

El juez no puede dejarse convencer solo por el discurso persuasivo del abogado en cuanto le es exigible conocer el proceso y determinar las pruebas que han de orientar la estimación o desestimación definitiva de la pretensión. Por lo tanto, es exigible someter las propuestas persuasivas al tamiz de la validación de los argumentos que exponen las partes, independientemente del nivel de persuasión de sus pretensiones.

En términos de Atienza, ${ }^{23}$ Perelman rehabilita la lógica, planteando la retórica como una práctica argumentativa cuyo objetivo consiste en captar

\footnotetext{
${ }^{22}$ GUASTINI, Ricardo. «Distinguiendo. Estudios de teoría y metateoría del Derecho». Gedisa. Barcelona, 1999. p. 216.

${ }_{23}$ Perelman, Chaim. «La nueva Retórica». En Las Razones del Derecho de Manuel AtienZA, p. 87.
} 
la adhesión de alguien. PERELMAN intentó construir una lógica específica de los valores y pretendió conducir la rehabilitación de la retórica como una disciplina de la antigüedad.

Este autor polaco contrapone dos esferas bien distintas del pensamiento: la lógica formal, regida por la idea de necesidad, y la argumentación, presidida por la idea de lo plausible, aceptable, verosímil. De esa razonabilidad nace la noción de un auditorio que ha de adherirse a un argumento.

La retórica, según PeRELMAN, es pues el estudio de las técnicas discursivas que tratan de provocar la adhesión a tesis presentadas a un determinado auditorio, excluyendo la violencia.

Representan elementos de la actividad argumentativa: el orador, el discurso y el auditorio. Para dicho autor, existen varios tipos de auditorio: universal, formado por todos los seres de la razón, aquel constituido por un único oyente (en el cual hay diálogo), y el constituido por uno mismo. Finalmente, los tipos de argumentación que invoca son: persuasiva, cuando se dirige a un auditorio particular, y convincente, cuando se desenvuelve el orador ante un auditorio universal.

Como crítica, ATIENZA advierte que la noción de auditorio universal es ambigua y sin embargo, le reconoce el esfuerzo por desarrollar el nivel de persuasión en la argumentación.

Llevadas las propuestas de PERELMAN a nuestra realidad, es importante destacar la necesidad de que el discurso argumentativo preste necesaria atención a la exigencia de persuadir, labor que no puede el abogado hacer a un lado en tanto la construcción de sus argumentos de defensa, o de imputación si nos referimos al ámbito de los fiscales en tanto representan también la pretensión punitiva del Estado, exige un esfuerzo de argumentación desde una posición exigiblemente persuasiva.

¿Debe el juez persuadir con su decisión? Consideramos que ésta es una manifestación implícita de la decisión judicial, pero junto a este rol de naturaleza del mensaje del juez, adquiere mayor noción de relevancia el rol cognitivo-racional, conforme reseñamos supra, es decir, tendrá que proceder el juez, por sobre las manifestaciones argumentativas de la persuasión, a definir racionalmente cuál es la fuerza probatoria de las pruebas aportadas y en qué medida ese rol cognitivo inclina su labor hacia una tarea mucho más objetiva, fuera de los apasionamientos que bien puede denotar el rol persuasivo. 


\subsection{El discurso racional de AlEXY}

En 1978, surgen las teorías modernas o estándar de la argumentación jurídica: de Robert ALEXY' ${ }^{24}$ (Oldenburg, Alemania, 1945) y de Neil MAC CORMICK ${ }^{25}$ (Glasgow, Escocia, 1941-Edimburgo, Escocia, 2009), las cuales perfilan en conjunto, una referencia al análisis teórico de los procesos argumentativos en el derecho.

La teoría de la argumentación jurídica pretende la descripción, conceptualización y sistematización del razonamiento y en sí, representa un metalenguaje, un metadiscurso con sus propios instrumentos y sus propios presupuestos.

Así, conforme señala MATHEUS ${ }^{26}$, mientras el discurso de los juristas se inclina por el análisis de la pena, el recurso, el dolo y la negligencia, el metadiscurso de las teorías de la Argumentación Jurídica hará referencia a la premisa normativa, la lógica deóntica, la situación ideal del diálogo y el argumento de la universalización, entre otras ideas.

El discurso racional de ALEXY revela, a juicio nuestro, uno de los aportes más significativos a la teoría de la argumentación jurídica, pues en función al aporte de razones válidas, congruentes y consistentes, se busca discernir sobre la validez del discurso jurídico que identifica a la decisión jurídica.

Revisar los postulados de ALEXY significa asociar sus ideas a las tendencias de la ponderación y la proporcionalidad, en las cuales es importante rescatar el rol que juega la importancia del discurso racional respecto a la argumentación jurídica y en efecto, por sobre las críticas formuladas a la ponderación de intereses y el principio de proporcionalidad, estimamos que es válido concluir que ponderación y proporcionalidad no constituyen, en modo alguno, expresiones de subjetividad ni posiciones particulares que escapan al examen de los juicios de validez jurídica. Por el contrario, la tesis de ALEXY se ciñe a que en el discurso racional un papel de suyo relevante, lo juega el aporte de razones.

\footnotetext{
${ }^{24}$ AleXY, Robert. «La Teoría de la Argumentación Jurídica». En Las Razones del Derecho de Manuel Atienza. p. 227.

25 MACCoRmicK, Neil. «Legal Reasoning and Legal Theory». En Las Razones del Derecho de Manuel Atienza. p. 167.

26 Matheus. Carlos. «Normas y silogismo jurídico». Materiales enseñanza Razonamiento Jurídico. PROFA. II nivel. Lima, 2004.
} 
Las posiciones de ALEXY han sido ampliamente difundidas en el mundo del Derecho contemporáneo, desde diversas obras ${ }^{27}$ y aportes, en la idea de sumar fuerza a la ponderación que en propiedad denomina balancing, desde la definición inglesa, y Abwägung, desde la doctrina alemana, en la idea matriz de que los principios, cuyo mejor ejemplo son los derechos fundamentales, pueden ser pesados y a partir de esa colisión, destacar que un principio se impone a otro.

Es de anotarse que esta propuesta puede ser blanco de objeciones: Jürgen HABERMAS considera que ALEXY ha abordado equivocadamente sus presupuestos de filosofía del lenguaje y Paolo COMMANDUCCI critica que los principios sean abordados como elementos de definición de una controversia dada su indeterminación, al tiempo que García AMADO objeta la subjetividad del método de la ponderación, pauta a la que debemos agregar la crítica de Luigi FERRAJOLI en cuanto considera que la ponderación es un equívoco muy grave que debilita la normativa constitucional.

Y sin embargo, es necesario observar que la ponderación aspira a identificar una lógica procedimental en cuanto su aplicación propiamente dicha a través del test de proporcionalidad, identifica tres sub exámenes que en rigor son los pasos de idoneidad o adecuación, necesidad y ponderación o proporcionalidad en sentido estricto, cuyo rigor de sistematización ha venido siendo una constante en la construcción abstracta de la teoría de ALEXY, y que ha sido criterio rector de pronunciamiento en diversas sentencias emblemáticas de la propia jurisprudencia peruana ${ }^{28} \mathrm{y}$ de diversos ordenamientos constitucionales en el Derecho Comparado ${ }^{29}$.

\section{CONCLUSIONES DE INTERÉS}

No obstante las pinceladas trazadas a modo de introducción, percibimos que nuestro análisis aún exige mucho por desarrollar dadas las premisas entimemáticas de la argumentación, es decir, que no pueden explicitarse en lo sostenido todas las ideas por excelencia concurrentes para una mejor justificación.

27 Cfr. AlEXY, Robert. «Teoría de la argumentación jurídica». Palestra Editores. Lima, 2007. Cfr. AlEXY, Robert. «Teoría de los derechos fundamentales». Centro de Estudios Políticos y Constitucionales. Madrid. 2002.

28 STC 045-2004-AI/TC, caso PROFA; STC 007-2006-PI/TC, caso calle de las Pizzas; STC 032-2010-PI/TC, caso Ley del Tabaco; STC 037-2012-PA/TC, caso Scotiabank; entre otros casos.

${ }^{29}$ Fundamentalmente Corte Constitucional de Colombia, Tribunal Constitucional español y la propia Corte Interamericana de Derechos Humanos (vid. caso Kimel vs Argentina. FF.JJ. 68-95) 
A pesar de ello, algunos esbozos han merecido nuestro interés principal en la medida que hemos graficado ideas de entrada a propósito de la importancia de argumentar y la percepción de la importancia de ese quehacer por parte de quienes tenemos la responsabilidad de asumir decisiones a diario a propósito de definir controversias jurídicas.

Es en ese tráfago de exigible justificación, que diferenciar los contextos de descubrimiento y de justificación, coadyuvan a que separemos, en la decisión judicial, nuestros motivos personales de las razones realmente justificativas de la decisión, en la necesidad de que sean excluidos prejuicios, inferencias subjetivas y cuestiones de idiosincracia del juicio jurídico.

Sobre esa separación necesaria, tiene lugar la justificación interna, a efectos de excluir juicios contradictorios, y la justificación externa, en referencia a una adecuada corrección material de las premisas, aspectos ambos necesarios para la validación suficiente de la razón judicial.

Por último, hemos querido brindar algunos lineamientos de reflexión de algunas de las varias importantes teorías de la argumentación jurídica, habiendo excluido, por temas de espacio, otros aportes de valor cuya data sería muy extenso enunciar.

Quedémonos sin embargo, con la idea fuerza de que la construcción de argumentos representa una tarea ciertamente compleja: miles de vicisitudes en el camino del razonamiento podrían bien variar en el camino de la solución de la controversia y a pesar de estar persuadidos de una justa solución en el caso concreto, bien podría conducirnos la existencia de soluciones múltiples a que pensemos, en paráfrasis, en la existencia del genio maligno del cual hablaba Descartes, haciéndonos creen en una solución pero encontrarnos prestamente otra inclusive mejor argumentada, lo cual podría conducir a un camino sine die de razones.

Pues ello no es estrictamente así. La construcción de argumentos implica el aporte de las mejores razones posibles para las cuales recurrimos a las herramientas más óptimas que la disciplina de la argumentación nos proporciona. Ese camino es de un permanente esfuerzo por desarrollar herramientas, alternativas y mejores recursos para brindar soluciones sociales en justicia. Es un reto al que no podemos renunciar. 


\section{REFERENCIAS BIBLIOGRÁFICAS}

ALEXY, Robert. Teoría de la argumentación jurídica. Palestra Editores. Lima 2007.

ALEXY, Robert. Teoría de los derechos fundamentales. Centro de Estudios Políticos y Constitucionales. Madrid, 2002.

ATIENZA, Manuel. DIEZ CONSEJOS PARA ARGUMENTAR BIEN O DECÁLOGO DEL BUEN ARGUMENTADOR. DOXA, Cuadernos de Filosofía del Derecho, No. 29 (2006).

AtienZA, Manuel. Las razones del Derecho. Palestra- Lima, 2004. .

BOBBIO, Norberto. El problema del positivismo jurídico. Fontamara, México, 1991.

BobBio, Norberto.Teoría del Ordenamiento Jurídico, 1960. En Introducción al Derecho de José Luis del Hierro. Editorial Síntesis, Madrid, 1997.

GARCIA FigueroA, Alfonso y Marina GASCÓN Abellán. La argumentación en el derecho. Algunas cuestiones fundamentales. Palestra Editores, Lima, 2003.

GASCÓN ABELLÁN, Marina. Los argumentos de la interpretación. En Razonamiento Jurídico. XII Curso de Ascenso Academia de la Magistratura.

GuASTINI, Ricardo. Distinguiendo. Estudios de teoría y metateoría del Derecho. Gedisa. Barcelona, 1999.

LUCAS Verdú, Pablo La lucha contra el positivismo jurídico en la República de Weimar. La teoría constitucional de Rudolf Smend, Ed. Tecnos, Madrid, 1987. En Revista de Estudios Políticos (Nueva Época). Núm. 59. Enero-Marzo 1988.

MATHEUS. Carlos. Normas y silogismo jurídico. Materiales enseñanza Razonamiento Jurídico. PROFA. II nivel. Lima, 2004.

Morelli, Mariano G. Pensar el derecho desde el problema. Theodor VIEHWEG: tópica y sistema en la historia del derecho. Disponible en http:/ / www.cartapacio. edu.ar/ojs/index.php/iyd/article/viewFile/815/1446 p. 6

SANTA CRUZ, Julio César. Razonamiento Jurídico. Diplomatura de Formación Profesional para Jueces del Segundo y Tercer Nivel de la Magistratura. Academia de la Magistratura, 2010. 